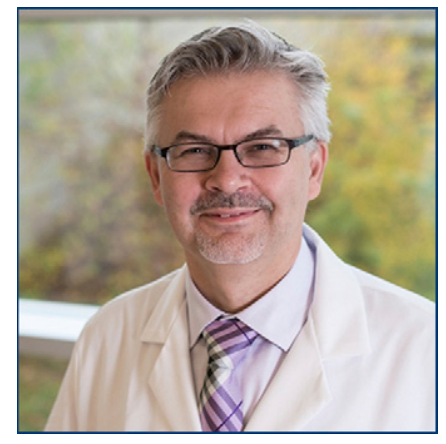

MARCIN CHWISTEK, MD, FAAHPM

Marcin Chwistek, MD, FAAHPM, is Director of the Pain and Palliative Care Program and an Associate Professor in the Department of Hematology and Oncology at Fox Chase Cancer Center, Philadelphia, Pennsylvania.

\section{Cancer, Cannabis, and the Search for Relief}

\author{
Marcin Chwistek, MD, FAAHPM
}

"H ow about medical marijuana?" is a common and often challenging question in oncology clinics today. It is easy to see why. Answering the question is fraught with clinical, legal, and administrative uncertainties. We all want to give patients the best advice, but not much about medical cannabis seems straightforward today. Whatever answer we provide can feel unsatisfactory to patients or ourselves. Answering clinical questions through high-quality research will take many years. And significant political power will be needed to clarify many of the legal and administrative hurdles. In the meantime, how should we approach patients who inquire about medical cannabis?

A retrospective study by Chang et $\mathrm{al}^{1}$ in this issue of the journal points to an intriguing observation: patients who use medical cannabis seem to have less adequate symptom control than those who do not. In the study, researchers analyzed charts of patients in an outpatient supportive care clinic at a cancer center. At the visit, clinicians assessed patients using the 11-point numerical Edmonton Symptom Assessment Scale (ESAS) and also obtained routine urine drug testing (UDT) to ensure safe prescribing. The charts of those who underwent both ESAS and UDT on the same day were further analyzed. The study found that $22.9 \%$ of the patients had cannabis metabolites in their urine. These patients were more likely to be young and male and reported more frequent cannabis use. However, as the analyses of their ESAS showed, they also self-reported a higher severity of pain, nausea, and insomnia, and worse overall and spiritual well-being compared with those who did not have positive UDT results. The use of cannabis in this group may be related to a number of factors. The authors postulated that inadequate control of symptoms drove the interest in and use of cannabis, which is consistent with other research. ${ }^{1}$

Patients with cancer are among the most frequent users of medical cannabis. Yet, the exact prevalence of cannabis use in these patients is not well established. In a recent survey conducted at a cancer center in Canada, 1 in 5 surveyed patients had used cannabis within the preceding 6 months; $46 \%$ of the users used it for cancerrelated pain; $34 \%$ for cancer-related nausea; and $31 \%$ for other cancer symptoms. ${ }^{2}$ In an anonymous survey conducted at the Seattle Care Alliance, $24 \%$ of responders considered themselves active cannabis users. ${ }^{3}$ Of all responders, $26 \%$ used it with intent to treat their cancer. They listed pain, nausea, and loss of appetite as the main reasons for their use. Responders also admitted to using cannabis recreationally. ${ }^{3}$

Patients with cancer experience a high symptom burden that tends to increase with disease progression. Many of the symptoms remain inadequately managed throughout the trajectory of the illness. ${ }^{4}$ Moreover, as surveys confirm, cannabis users see cannabis-based products as safe, devoid of dangerous interactions, and useful for symptom control and even for the treatment of cancer. Unfortunately, only some of these many hopes are backed by clinical evidence. Meanwhile, across the United States, cannabis has gained a more positive public image that helped fuel the burgeoning industry. That patients with cancer reach for cannabis for symptom relief is hardly surprising.

Humans have cultivated and used cannabis for thousands of years. The oldest written report about its medical use comes from the Chinese Emperor Shen Nung, who wrote about it in the 28th century BCE. Modern cannabis research started in

See page 1059 for related article.
The ideas and viewpoints expressed in this commentary are those of the author and do not necessarily represent any policy, position, or program of NCCN. 
the early 1960s when Gaoni and Mechoulam first isolated delta-9-tetrahydrocannabinol (THC) from a group of more than 60 cannabis constituents. ${ }^{5}$ Two decades later, they discovered how THC exerts its effects on cellular function through the cannabinoid type 1 receptor (CB1). Another receptor, CB2, was cloned a few years later. Then, in the early 1990s, endogenous cannabinoids (endocannabinoids), anandamide and 2AG, were isolated. These discoveries created the basis for our understanding of the endocannabinoid system. ${ }^{5}$ The system has a modulatory effect on a host of physiologic processes such as mood, memory, appetite, and pain modulation. The exploitation of it could contribute to new advances in treating many health-related issues, many of them relevant to patients with cancer. ${ }^{5}$ This idea has engrossed the interests of cancer researchers, clinicians, and patients.

Despite its promise, the modern cannabis-based armamentarium of approved pharmaceuticals is quite sparse. In the United States, the Federal Drug Administration's designation of cannabis as a schedule I drug (no medicinal value, high abuse potential) has thwarted research for decades. The first cannabis-based drug, dronabinol (synthetic THC), was approved in 1986. It was later followed by nabilone, another synthetic THC. Both were approved for the treatment of nausea and vomiting related to chemotherapy. Dronabinol has also received an indication for cancer-related cachexia. More recently, nabiximols was approved in Canada and many European countries. It is a whole plant extract that contains both THC and CBD in a 1:1 ratio. Nabiximols showed promise in clinical trials for the treatment of spasticity in multiple sclerosis and neuropathic pain. The drug is not yet available in the United States. The newest cannabis-based medication is cannabidiol. The FDA has approved it for treatment-resistant seizure disorder. ${ }^{6}$

The scarcity of cannabis-based pharmaceuticals stands in stark contrast to the widespread availability of commercial plant based-products. Edibles, oils, tablets, and tinctures are available for patients via state-approved dispensaries. The vast majority of clinical research, however, still comes from studies of the isolated THC pharmaceuticals or the oromucosal whole plant extract, nabiximols. This creates a disconnect between what we know through research and what is available for patients. In 2017, the US National Academies of Sciences, Engineering, and Medicine published a lengthy report: "Health Effects of Cannabis and Cannabinoids." Experts analyzed scores of studies. They concluded that although some evidence is available supporting the use of medical cannabis in several conditions, the evidence is limited and overall of poor quality. The most substantial evidence exists for the treatment of pain, especially neuropathic pain, and for nausea and vomiting associated with chemotherapy. Less robust data exist for other commonly encountered symptoms such lack of appetite and insomnia. Additionally, cannabis may also have opioid-sparing effects. This could be helpful for many of the patients with cancer who are on longterm opioid therapy. ${ }^{8}$

Cannabis use is not devoid of risks. Approximately 1 in 8 chronic cannabis users will develop cannabis use disorder. Acutely, THC impairs attention, concentration, associative learning, and motor coordination. It may increase anxiety and agitation, and in some cases of high consumption it may cause confusion and hallucinations. Physiologically, it causes dryness of the mouth, red eyes, tachycardia, and increased appetite. However, cannabis does not cause respiratory depression. Contrary to opioids, death from overdose is impossible with cannabis alone. ${ }^{9}$

Advising patients about use of medical cannabis can be dizzying. First, there is insufficient high-quality research, potential risks associated with its use, and interactions with medications. Additionally, concerns related to the quality of cannabis products, lack of information about dosing, and confusing legal status are problematic. It is not at all surprising that about one third of surveyed oncologists who discussed medical cannabis with their patients did not feel comfortable doing so. Yet, patients with cancer who are already using medical cannabis are finding it helpful in addressing a range of cancer-related symptoms. They also want to discuss its use with their oncologist. ${ }^{10}$ The question, "How about medical marijuana?" should not be left unanswered. We have a responsibility to educate ourselves and our patients.

At the same time, patients posing the question in a busy clinic might be also a signal to pause. Much of oncology today is about moving forward. We do tests, design treatment paths, and administer treatment. In contrast, symptoms are how patients experience their illness. When severe or challenging to control, symptoms can slow progress or make moving ahead impossible.

Thus, clinicians can choose to see the question as an invitation for a more in-depth discussion with patients about their symptoms, their coping, and their experience of illness. If we answer to this question, we can use the moment as an opportunity to make our partnership with our patients deeper, more trusting, and more meaningful, for the patients and ourselves.

\section{References}

1. Chang YD, Jung JW, Oberio-Jassal R, et al. Edmonton Symptom Assessment Scale and clinical characteristics associated with cannabinoid use in oncology supportive care outpatients. J Natl Compr Canc Netw 2019;17:1059-1064.

2. Martell K, Fairchild A, LeGerrier B, et al. Rates of cannabis use in patients with cancer. Curr Oncol 2018;25:219-225.

3. Pergam SA, Woodfield MC, Lee CM, et al. Cannabis use among patients at a comprehensive cancer center in a state with legalized medicinal and recreational use. Cancer 2017;123:4488-4497.

4. van den Beuken-van Everdingen MH, Hochstenbach LM, Joosten EA, et al. Update on prevalence of pain in patients with cancer: systematic review and meta-analysis. J Pain Symptom Manage 2016;51:1070-1090. 
5. Mechoulam R, Parker LA. The endocannabinoid system and the brain. Ann Rev Psychol 2013;64:21-47.

6. Birdsall SM, Birdsall TC, Tims LA. The use of medical marijuana in cancer. Curr Oncol Rep 2016;18:40.

7. National Academies of Sciences, Engineering, and Medicine. The health effects of cannabis and cannabinoids: current state of evidence and recommendations for research. Washington, DC: National Academies Press; 2017
8. Abrams DI. Should oncologists recommend cannabis? Curr Treat Options Oncol 2019;20:59

9. National Cancer Institute. Cannabis and cannabinoids (PDQ)-health professional version. Available at: https://www.cancer.gov/about-cancer/ treatment/cam/hp/cannabis-pdq. Accessed August 12, 2019

10. Braun IM, Wright A, Peteet J, et al. Medical oncologists' beliefs, practices, and knowledge regarding marijuana used therapeutically: a nationally representative survey study. J Clin Oncol 2018;36:1957-1962.

\section{Statement of Ownership, Management and Circulation (Requester Publication)}

1) Publication Title: JNCCN_Journal of the National Comprehensive Cancer Network. 2) Publication Number: 1540-1405. 3) Filing Date: 9/13/2018. 4) Monthly, expect semi-monthly in May + November. 5) Number of Issues Published Annually: 14. 6) Annual Subscription Price (if any): \$935.00. 7) Complete Mailing Address of Known Office of Publication: Harborside Press LLC, 94 North Woodhull Road, Huntington, Suffolk, NY 11743. Contact Person: John Gentile. Telephone: 631-935-7655. 8) Complete Mailing Address of Headquarters or General Business Office of Publisher: Harborside Press LLC, 94 North Woodhull Road, Huntington, Suffolk, NY 11743. 9) Full Names and Complete Mailing Addresses of Publisher, Editor, and Managing Director: Publisher: John A. Gentile Jr, Harborside Press LLC, 94 North Woodhull Road, Huntington, Suffolk, NY 11743. Editor: Margaret Tempero MD, University of California, San Francisco Mission Bay Campus, 550 16th Street, 6th Floor, Box 3211, San Francisco, CA 94143. Managing Editor: Kimberly A. Callan, MS, ELS, National Comprehensive Cancer Network, 3025 Chemical Road, Suite 100, Plymouth Meeting, PA 19462. 10) Owner: Full Name: Harborside Press LLC, John A. Gentile Jr (Principal), Anthony Cutrone (Principal), Conor Lynch (Principal). Complete Mailing Address: 94 North Woodhull Road, Huntington, Suffolk, NY 11743. 11) Known Bondholders, Mortgagees, and Other Security Holders Owning or Holding 1 Percent or More of Total Amount of Bonds, Mortgages, or Other Securities: None. 12) Tax Status: N/A. 13) Publication Title: JNCCN_Journal of the National Comprehensive Cancer Network. 14) Issue Date for Circulation Data Below: July 2019. 15) Extent and Nature of Circulation - Average No. Copies Each Issue During Preceding 12 Months. a) Total Number of Copies (Net press run): 27,066. b) Legitimate Paid and/or Requested Distribution (By Mail and Outside the Mail) (1) Outside County Paid/Requested Mail Subscriptions stated on PS Form 3541: 11,942. (2) In-County Paid/Requested Mail Subscriptions stated on PS Form 3541: N/A. (3) Sales Through Dealers and Carriers, Street Vendors, Counter Sales, and other Paid or Requested Distribution Outside USPS®: N/A. (4) Requested Copies Distributed by Other Mail Classes Through the USPS (e.g. First-Class Mail ${ }^{\oplus}$ : 0 c) Total Paid and/or Requested Circulation (sum of 15b (1), (2), (3), and (4): 11,942. d) Nonrequested Distribution (By Mail and Outside the Mail) (1) Outside County Nonrequested Copies Stated on PS Form 3541: 12,047. (2) In-County Nonrequested Copies Stated on PS Form 3541: N/A. (3) Nonrequested Copies Distributed Through the USPS by Other Classes of Mail: N/A. (4) Nonrequested Copies Distributed Outside the Mail: 67 e) Total Nonrequested Distribution (Sum of 15d (1), (2), (3) and (4)) 12,114. f) Total Distribution (Sum of 15c and e): 24,056. g) Copies not Distributed: 3010. h) Total (Sum of $15 \mathrm{f}$ and g) 27,066. i) Percent Paid and/or Requested Circulation: 50\%. 15) Extent and Nature of Circulation - No. Copies of Single Issue Published Nearest to Filing Date. a) Total Number of Copies (Net press run): 27,629. b) Legitimate Paid and/or Requested Distribution (By Mail and Outside the Mail) (1) Outside County Paid/Requested Mail Subscriptions stated on PS Form 3541: 12,950. (2) In-County Paid/Requested Mail Subscriptions stated on PS Form 3541: N/A. (3) Sales Through Dealers and Carriers, Street Vendors, Counter Sales, and other Paid or Requested Distribution Outside USPS ${ }^{\oplus}$ : N/A. (4) Requested Copies Distributed by Other Mail Classes Through the USPS (e.g. First-Class Mai ${ }^{\circledR}$ ): 0. c) Total Paid and/or Requested Circulation (sum of 15b (1), (2), (3), and (4): 12,950. d) Nonrequested Distribution (By Mail and Outside the Mail) (1) Outside County Nonrequested Copies Stated on PS Form 3541: 12.415. (2) In-County Nonrequested Copies Stated on PS Form 3541: N/A. (3) Nonrequested Copies Distributed Through the USPS by Other Classes of Mail: N/A. (4) Nonrequested Copies Distributed Outside the Mail: 60. e) Total Nonrequested Distribution (Sum of 15d (1), (2), (3), and (4)) 14,578. f) Total Distribution (Sum of $15 \mathrm{c}$ and e): 25,365 . g) Copies not Distributed: 2264. h) Total (Sum of $15 f$ and g) 27,629. i) Percent Paid and/or Requested Circulation: $51 \%$. 16) Total circulation does not include electronic copies. 17) Publication of Statement of Ownership for a Requester Publication is required and will be printed in the September 2019 issue of this publication. 18) Signature and Title of Editor, Publisher, Business Manager, or Owner: John A. Gentile Jr, Publisher. Date: $9 / 13 / 2018$. I certify that all information furnished on this form is true and complete. I understand that anyone who furnishes false or misleading information on this form or who omits material or information requested on the form may be subject to criminal sanctions (including fines and imprisonment) and/or civil sanctions (including civil penalties). 